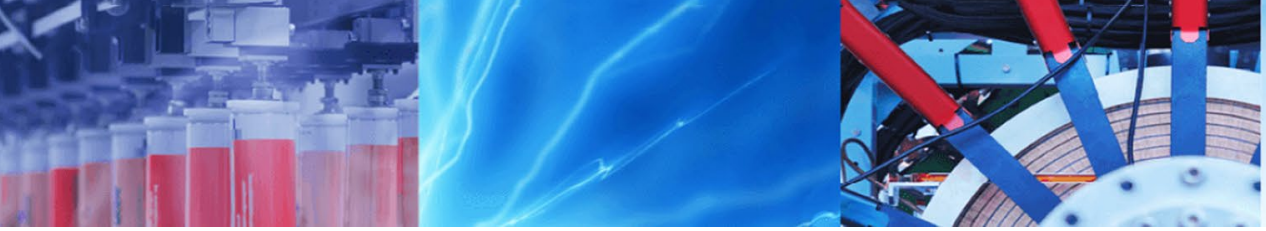

Research Article

\title{
Validation of a modified QuEChERS method to determine multiclass multipesticide residues in apple, banana and guava using GC-MS and LC-MS/MS and its application in real sample analysis
}

\author{
Swagata Mandal ${ }^{1,2} \cdot$ Rajlakshmi Poi $^{1}$ - Inul Ansary ${ }^{2} \cdot$ Dipak Kumar Hazra $^{1} \cdot$ Sudip Bhattacharyya ${ }^{1} \cdot$ Rajib Karmakar $^{1}$
}

Received: 14 November 2019 / Accepted: 6 January 2020 / Published online: 10 January 2020

(c) Springer Nature Switzerland AG 2020

\begin{abstract}
A modified QuEChERS method was developed for the determination of 64 pesticides in apple, guava andbanana using GC-MS and LC-MS/MS. Out of sixty-four pesticides, 39 (32 insecticides + 7 herbicides) were analysed by GC-MS and others were analysed in LC-MS/MS. The efficiency of methanol, ethyl-acetate and acetonitrile as extracting solvents were checked. Among these, acetonitrile gave the highest recovery. d-SPE clean-up was done for apple and guava using PSA, whereas PSA + GCB was used for banana to remove heteropolysaccharides and carotenoids. The method was validated as per SANTE/11813/2017 guidelines. The LOD was in the range of $0.002-0.04 \mathrm{mg} \mathrm{kg}^{-1}$ and LOQ was $0.005-0.11 \mathrm{mg} \mathrm{kg}^{-1}$. Average recovery ranged from 80 to $120 \%$ with RSD $\leq 20 \%$ and RPD $\%$ of precision $\leq 20 \%$. The expanded uncertainty was $\leq 20 \%$. The validated method was applied to check the real samples of apple, guava and banana collected from markets of four different districts of West Bengal, India.
\end{abstract}

Keywords QuEChERS · Pesticides · Apple · Guava ·Banana - LC/MS/MS · GC/MS

\section{Introduction}

The nutritional intake from fruits and vegetables is higher among urban population than that of rural population. Along with the urbanisation, people are likely to increase their calorie intake at a higher pace through fruits and vegetables [1]. Apple, banana, guava are the most produced and consumed fruits around the world. India was the highest producer of guava and banana and fifth highest producer of apple around the world [2].During 2018-2019, India exported fruits and vegetables worth Rs. 10236.93 crores/1,469.33 USD Millions which comprised of fruits worth Rs. 4817.35 crores/692.01 USD Millions and vegetables worth Rs. 5419.48 crores/777.25 USD Millions [3]. During cultivation in Indian climaticcondition, fruits suffer a lot of problem due to attack of pest and diseases that would make yield reduction as well as downturn the food quality. The use of pesticidesthereforeis becoming necessary and the residues of which are coming in food matrices with an elevated amount.

The wide-range use of pesticides and their highly persistent nature are the major affair for the availability of the residue in environment and food stuffs. The presence of residue in food with high level to the consumers is the thing of global concern. Due to this fact, these pesticidesmust be documented and precisely scanned. Several methods have been reported for the analysis of multiclass pesticide residues in fruit matrices, associating soxhlet extraction [4], liquid-liquid extraction (LLE) [5], matrix solid phase dispersion (MSPD) [6], microwave assisted extraction (MAE) [7], accelerated solvent extraction (ASE) [8], ultrasound extraction [9] and solid phase

\footnotetext{
$\triangle$ Rajib Karmakar, rajibc183@rediffmail.com | ${ }^{1}$ All India Network Project On Pesticide Residue Laboratory, Directorate of Research, Bidhan Chandra Krishi Viswavidyalaya, Kalyani, Nadia, West Bengal 741235, India. ${ }^{2}$ Department of Chemistry, Burdwan University, Bardhaman, West Bengal 712104, India.
} 
extraction (SPE) $[10,11]$.These methods have been used with limited success. To optimize and detect the pesticides, therefore a simple, rapid and cost-effective method is needed. Anastassiadesand his co-workers [12] developed a multi residue method for the analysis of pesticide residue from food samples, known as QuEChERS. Considering the fact, a modified QuEChERSmethod [13] have been developed to detect residues of multipesticides using gas chromatography coupled with single quadrupole and liquid chromatography associated with triple quadrupole, without any hint on cleaning up of banana matrix. A total of sixty-four pesticides were chosen based on the report that apple, guava and banana growing farmers are usually spraying these pesticides in India. It is important to monitor residue levels of these pesticides in these raw consumable fruits. Based on the polarities of the pesticidesGCMS and LC-MS/MS were chosen. Out of 64 pesticides, 39 (=31 insecticides including OCs, OPs and synthetic pyrethroids +1 tetronic acid insecticide spiromesifen +7 herbicides) pesticides were analysed with GC-MS and 25 pesticides were analysed with LC-MS/MS. The purpose of the study is to developmulti-class, multi-residue method based on QuEChERS for the analysis of above-mentioned pesticides which are frequently used in apple, guava and banana orchards. Also, the method shall assist to detect and determine the quantities of pesticide loads for monitoring of apple, guava and banana fruit meant for export.

\section{Materials and methods}

\subsection{CRMs, chemicals and apparatus}

All CRMs of 64 pesticideswith purity $\geq 98 \%$ were purchased from Dr.Ehrenstorfer (Augsburg, Germany). Individual mother stock solutions ( $500 \mathrm{mgL}^{-1}$ ) of $39 \mathrm{GC}$ amenable pesticides were prepared with hexane-toluene (1:1) mixture and that of $25 \mathrm{LC}$ amenable pesticides were prepared in acetonitrile.Intermediate stock solution $\left(100 \mathrm{mg} \mathrm{L}^{-1}\right)$ were prepared respectively in the same solvents, by appropriate dilution from the mother stock solution and were stored at $4{ }^{\circ} \mathrm{C}$.To prepare $10 \mathrm{mg} \mathrm{L}^{-1}$ mixture of 64 pesticides, the required volumes of intermediate stock solution of pesticides were added and hexene-toluene mixture, acetonitrile were evaporated in Tarbo-vap.The final volume was made with acetonitrile. Theworking standard solutions of $0.01,0.05,0.1,0.5$ and $1 \mathrm{mg} \mathrm{L}^{-1}$ prepared in acetonitrilefrom $10 \mathrm{mg} \mathrm{L}^{-1}$ for LC-MS/MS. Acetonitrile from the respective working standard solutionswere evaporated up and reconstituted in hexane for GC-MS. Matrix-matched standards of $0.01,0.05,0.1,0.5$ and $1.0 \mathrm{mg} \mathrm{L}^{-1}$ prepared by evaporating appropriate volumes of a standardmixturesolution and diluting withrespectivematrix of apple, guava and bananain hexane and acetonitrile respectively for use in GC-MS and LC-MS/MS. The working standard solutions were also stored at $4{ }^{\circ} \mathrm{C}$.Analytical grade $\mathrm{NaCl}$ and anhydrous $\mathrm{MgSO}_{4}$ were obtained from Merck, Darmstadt, Germany. The $\mathrm{MgSO}_{4}$ was baked for $5 \mathrm{~h}$ at $500{ }^{\circ} \mathrm{C}$ in a muffle furnace to remove phthalates. Primary Secondary Amine (PSA) and Graphitized Carbon Black (GCB) sorbent were purchased from Agilent Technology, USA.Ammoniumformate buffer (Bio-ultra $\geq 99.0 \%$ ) was procured from Fluka Milan, Italy. AnalyticalLC-MS grade acetonitrile, hexane, acetone, water, methanol and toluene were obtained from J.T. Baker, Avantor, USA. High precision calibrated analytical balance (Sartorius AG, Göttingen, Germany) was used for weighing the CRMs, reagents and samples accurately. A Robot Coupe Blixer 6V.V (7L) Vincennes, France was used to comminute the fruit samples. A vortex mixer (Spinix, Tarsons, Kolkata, India), Rotospin (Tarsons, Kolkata, India), Silent Crusher (Heidolph, Schwabach, Germany), Centrifuge (Super Spin R-V/FM Plasto Crafts, Mumbai, India) and Turbo Vap evaporator (Caliper Life Sciences, Hopkinton, Massachusetts, USA) were used for sample preparation. A solvent filtration unit (Borosil, India) and micropipettes (Boeco, Germany) of $1000 \mu \mathrm{l}, 5000 \mu \mathrm{l}$ and $10 \mathrm{ml}$, were used.

\subsection{Selection of pesticides and fruits}

Apple, guava and banana were selected for the study based on their export potential. All these sixty-four pesticides ( 50 insecticides, 8 fungicides and 6 herbicides) were selected for our study based on the report that farmers are using these pesticides in apple, guava and banana in India. Therefore, it is necessary to monitor their residue levels in raw consumable fruits. Apple (Malus domesticavar. Golden delicious), Banana (Musaacuminatevar.Singap uri) and Guava (Psidium guajavavar.Khaja) were randomly collected from the untreated control plots of research trials. These fruits were screened and confirmed that no any pesticidewas present before using these in the method developingprocess. Reals samples of apple, guava and banana were collected from the markets of Kolkata, Howrah, Hooghly and Burdwan districts of west Bengal, India. The samples were well comminuted, and placed in glass bottles, and stored at $-20^{\circ} \mathrm{C}$.

\subsection{Instrumentation}

GCMS-QP 2010 Plus (Shimadzu Corporation, Kyoto, Japan) with a mass selective detector (MSD, single quadrupole) and a Capillary column DB-5MS J\&W $30 \mathrm{~m} \times 0.25 \mathrm{~mm}$ id $\times 0.25 \mu \mathrm{m}$ (Agilent, USA,) was used for confirmation and quantification study. GC-MS operated under following GC conditions:Initial temperature $40^{\circ} \mathrm{C}$ for $1 \mathrm{~min}$, then increased $@ 25^{\circ} \mathrm{C} \mathrm{min}-1$ to $130^{\circ} \mathrm{C}$ and $@ 12^{\circ} \mathrm{Cmin}^{-1}$ 
to $180^{\circ} \mathrm{C}$ and again increased $@ 3^{\circ} \mathrm{Cmin}^{-1}$ to $280^{\circ} \mathrm{C}$, then hold for $7 \mathrm{~min}$. Injector temperature was $250^{\circ} \mathrm{C}$. Carrier gas used was Helium (purity $99.999 \%$ ). Ion source temperature was $250^{\circ} \mathrm{C}$. Interface temperature was $280^{\circ} \mathrm{C}$. The instrument operated in the spit mode with split ratio 1:10. Purge flow was $3 \mathrm{ml} \mathrm{min}^{-1}$. Injection volume was $2 \mu \mathrm{L}$. MS condition were as follows: delay solvent was 6 min; electron impact ionization voltage was $70 \mathrm{eV}$; scan rate was $0.50 \mathrm{~s}^{-1}$; scanned mass ranged $50-500 \mathrm{~m} / \mathrm{z}$. All samples wereanalysed in the Selected lon Monitoring (SIM) mode. Retention times, selected monitoring ions used for the identification and confirmation are depicted in Table 1.The LC-MS/MS analysis was carried out using an API-3200 LC-MS/MS system (AB Sciex, Vaughan, Canada)
Table 1 Optimization of different parameters of 39 pesticide CRMs in GC-MS

\begin{tabular}{|c|c|c|c|c|c|c|}
\hline \multirow[t]{3}{*}{ Pesticide } & \multicolumn{6}{|c|}{ GC-MS, SIM (min.) } \\
\hline & \multirow{2}{*}{$\begin{array}{l}\text { Retention } \\
\text { Time (min.) }\end{array}$} & \multicolumn{2}{|c|}{ Time (min.) } & \multicolumn{3}{|c|}{$\mathrm{m} / \mathrm{z}$ for confirmation with ion ratio } \\
\hline & & Start & End & Target $(\mathrm{T})$ & $\mathrm{Q}_{1}\left(\% \mathrm{Q}_{1} / \mathrm{T}\right)$ & $\mathrm{Q}_{2}\left(\% \mathrm{Q}_{2} / \mathrm{T}\right)$ \\
\hline 4-Br-2Cl-phenol & 8.96 & 8.44 & 9.14 & 208 & $172(42.09 \%)$ & $170(32.58 \%)$ \\
\hline Trifluralin & 13.61 & 13.574 & 13.79 & 306 & $43(44.72 \%)$ & $264(40.28 \%)$ \\
\hline Phorate & 14.31 & 14.30 & 14.43 & 75 & $121(50.28 \%)$ & $260(43.29 \%)$ \\
\hline Alpha-HCH & 14.59 & 14.43 & 14.71 & 181 & $183(93.37 \%)$ & $219(51.04 \%)$ \\
\hline Dimethoate & 14.96 & 14.81 & 15.12 & 87 & $93(51.23 \%)$ & $125(42.30 \%)$ \\
\hline Atrazine & 15.35 & 15.08 & 15.59 & 200 & $215(97.23 \%)$ & $58(76.68 \%)$ \\
\hline Beta-HCH & 15.52 & 15.49 & 15.87 & 181 & $183(68.78 \%)$ & $219(95.78 \%)$ \\
\hline Lindane & 15.76 & 15.59 & 15.87 & 181 & $183(96.48 \%)$ & $219(54.23 \%)$ \\
\hline Phosphamedon & 16.03 & 15.91 & 16.13 & 127 & $72(40.28 \%)$ & $264(40.89 \%)$ \\
\hline Chlorothalonil & 16.38 & 15.87 & 16.43 & 266 & $264(76.28 \%)$ & $268(50.23 \%)$ \\
\hline Delta-HCH & 16.92 & 16.83 & 17.04 & 181 & $183(92.49 \%)$ & $219(57.85 \%)$ \\
\hline Dimethachlor & 17.76 & 17.69 & 17.86 & 134 & 197 (40.23\%) & 77 (52.91\%) \\
\hline Parathion-methyl & 18.31 & 18.25 & 18.45 & 263 & 109 (42.21\%) & $125(35.23 \%)$ \\
\hline Alachlor & 18.30 & 18.22 & 18.45 & 45 & $160(42.28 \%)$ & $188(26.22 \%)$ \\
\hline Heptachlor & 18.71 & 18.65 & 18.84 & 100 & $272(42.28 \%)$ & $274(30.56 \%)$ \\
\hline Malathion & 19.80 & 19.71 & 19.92 & 125 & 127 (65.59\%) & 93 (47.54\%) \\
\hline Chlorpyriphos & 20.14 & 19.92 & 20.23 & 97 & 197 (63.28\%) & 199 (41.56\%) \\
\hline Aldrin & 20.36 & 20.23 & 20.50 & 66 & $263(57.63 \%)$ & 91 (22.73\%) \\
\hline Pendimethylene & 21.77 & 21.50 & 21.90 & 252 & 162 (18.93\%) & $181(20.43 \%)$ \\
\hline Quinalphos & 22.85 & 21.70 & 22.96 & 146 & $118(65.00 \%)$ & $156(61 \%)$ \\
\hline OP-DDD & 23.72 & 23.62 & 23.80 & 235 & 165 (76.43\%) & 237 (53.85\%) \\
\hline Butachlor & 23.87 & 23.70 & 24.02 & 57 & 176 (68.89\%) & $160(76.31 \%)$ \\
\hline Alpha-endo & 24.18 & 24.02 & 24.46 & 241 & 195 (80.25\%) & 159 (22.91\%) \\
\hline PP-DDD & 24.91 & 24.56 & 25.05 & 235 & 165 (56.28\%) & 237 (32.50\%) \\
\hline Profenophos & 25.20 & 25.10 & 25.35 & 337 & 97 (68.11\%) & 139 (66.97\%) \\
\hline PP-DDE & 25.39 & 25.20 & 24.56 & 246 & $318(75.76 \%)$ & $248(54.81 \%)$ \\
\hline OP-DDT & 25.75 & 25.58 & 25.82 & 235 & $165(40.12 \%)$ & $237(32.20 \%)$ \\
\hline Beta-Endosulfan & 27.42 & 27.25 & 27.52 & 241 & 195 (65.23\%) & $159(40.21 \%)$ \\
\hline Ethion & 27.77 & 27.62 & 27.80 & 231 & 97 (60.28\%) & $153(50.78 \%)$ \\
\hline PP-DDT & 27.77 & 27.62 & 27.80 & 235 & 165 (52.28\%) & $237(61.12 \%)$ \\
\hline Endo sulphate & 29.67 & 29.52 & 29.95 & 272 & 274 (53.37\%) & 239 (50.21\%) \\
\hline Spiromesifen & 31.70 & 31.55 & 31.95 & 272 & $99(52.23 \%)$ & $273(36.16 \%)$ \\
\hline Bifenthrin & 32.91 & 32.74 & 33.12 & 181 & 166 (53.27\%) & 165 (62.74\%) \\
\hline Fenpropathrin & 33.45 & 33.20 & 33.70 & 97 & 181 (96.97\%) & 265 (35.12\%) \\
\hline Lamda-cyhalothrin & 36.23 & 36.14 & 36.30 & 181 & 197 (95.70\%) & 208 (58.77\%) \\
\hline Beta-cyfluthrin & 41.24 & 41.07 & 41.40 & 163 & $206(65.23 \%)$ & $226(54.15 \%)$ \\
\hline Cypermethrin & 42.24 & 42.10 & 42.30 & 181 & $163(75.86 \%)$ & 127 (47.59\%) \\
\hline Fenvalerate & 44.76 & 44.60 & 44.92 & 125 & 167 (57.88\%) & 225 (44.54\%) \\
\hline Deltamethrin & 47.87 & 47.72 & 47.99 & 181 & 253 (72.62\%) & 77 (69.84\%) \\
\hline
\end{tabular}

C.R.M., certified reference materials; R.T., retention time; SIM., selected ion monitoring 
hyphenated to a Waters UPLC (USA) controlled by Analyst 1.5 software. The chromatographic separation was carried out injecting $10 \mu \mathrm{L}$ onto a reverse phase Zorbax SB-C18 $(4.6 \mathrm{~mm} \times 150 \mathrm{~mm} \times 5 \mu \mathrm{m})$ column (Agilent Technologies, USA) maintained at $35^{\circ} \mathrm{C}$ with mobile phase flow rate of $0.35 \mathrm{ml} \mathrm{min}^{-1}$. The mobile phase was composed of (A) $5 \mathrm{mM}$ ammonium formate in methanol and (B) $5 \mathrm{mM}$ ammonium formatein water. The gradient elution programme was as follows: A (95\%) B (5\%) at the initial time (0 min), A (95\%) B (5\%) (at $1.70 \mathrm{~min}), A(50 \%) B(50 \%)$ (at $4.90 \mathrm{~min}), A(10 \%) B(90 \%)$ (at $9.90 \mathrm{~min}), A(10 \%) B(90 \%)$ (at $11.50 \mathrm{~min}), A(95 \%) B(5 \%)$ (at $13.21 \mathrm{~min}), A(95 \%) B(5 \%)$ (at $14 \mathrm{~min}$ ). Total run time was $14 \mathrm{~min}$. The mass spectrometric analysis of all 25 pesticides performed were estimated in positiveelectrospray ionization mode [ESI (+ve)] with dwell time of $30 \mathrm{~ms}$. Here using two abundant precursor/ products were used for transition of ion in MS/MS analysis for the construction of MRM. The MS source condition was: The ion source temperature was set at $500{ }^{\circ} \mathrm{C}$, ion spray voltage was $5500 \mathrm{~V}$ in positivemode.Curtain gas of 30 psi, collisionally activated dissociation gas (CAD) of 5 psi, nebulizer gas (GS1) of 40 psi, heater gas of (GS2) 40 psi were used. The specific mass spectrometric parameters of 25 compounds were given in Table 2 . The identification and quantification were performed in samples and standards in accordance with the confirmation criteria of the EC guidelines.

\subsection{Sample preparation}

About $2 \mathrm{~kg}$ of fruit (apple, banana, guava) samples were collected from the untreated control plots of research trialsand chopped sample was homogenized in Robot Coupe Blixer @5000 rpm for $10 \mathrm{~min}$. The well comminuted samples were placed in glass bottles (Tarson make) and stored at $-20^{\circ} \mathrm{C}$ before analysis. For each substrate, $15 \mathrm{~g}$ homogenized sample was taken into three $50 \mathrm{ml}$ centrifuge tubes to optimize the extraction procedure and $15 \mathrm{ml}$ three different solvents i.e. methanol, ethyl-acetate and acetonitrile were added. Then vortexed for $1 \mathrm{~min}$. The mixture was then homogenized by Silent Crusher @ $12,500 \mathrm{rpm}$ for $1 \mathrm{~min} .1 .5 \mathrm{~g}$ of activated sodium chloride

Table 2 Optimization of instrument acquisition parameters of 25 pesticide CRMs in LC-MS/MS

\begin{tabular}{|c|c|c|c|c|c|c|c|c|}
\hline \multirow[t]{2}{*}{ Pesticides } & \multirow[t]{2}{*}{$\mathrm{RT}(\min )$} & \multirow{2}{*}{$\begin{array}{l}\text { Precursor ion } \\
(\mathrm{m} / \mathrm{z})\end{array}$} & \multicolumn{3}{|c|}{ First Transition quantification } & \multicolumn{3}{|c|}{ Second transition identification } \\
\hline & & & Product ion $(\mathrm{m} / \mathrm{z})$ & $\mathrm{DP}(\mathrm{V})$ & $\mathrm{CE}(\mathrm{V})$ & Product ion (m/z) & $\mathrm{DP}(\mathrm{V})$ & $\mathrm{CE}(\mathrm{V})$ \\
\hline Carbendazim & 5.31 & 19 & 160 & 33 & 30 & 132 & 33 & 43 \\
\hline Imidacloprid & 4.88 & 256 & 209 & 41 & 21 & 175 & 41 & 31 \\
\hline Thiacloprid & 5.01 & 253 & 126 & 61 & 25 & 90 & 61 & 55 \\
\hline Carbofuran & 5.32 & 222 & 165 & 61 & 23 & 123 & 61 & 29 \\
\hline Carbaryl & 5.36 & 202 & 145 & 31 & 17 & 127 & 31 & 39 \\
\hline Triazophos & 5.88 & 314 & 162 & 29 & 25 & 119 & 29 & 49 \\
\hline Monocrotophos & 4.76 & 224 & 127 & 31 & 21 & 98 & 31 & 17 \\
\hline Spirotetramet & 6.04 & 374.40 & 302.40 & 56 & 23 & 330.50 & 46 & 23 \\
\hline Tebuconazole & 6.54 & 308 & 70 & 61 & 55 & 125 & 61 & 59 \\
\hline Hexaconazole & 6.96 & 314 & 70 & 52 & 38 & 159 & 52 & 38 \\
\hline Anilophos & 6.30 & 368 & 199 & 55 & 20 & 171 & 55 & 29 \\
\hline Thiamethoxam & 4.73 & 292 & 211 & 46 & 19 & 181 & 46 & 31 \\
\hline Acetamiprid & 4.88 & 223 & 126 & 60 & 27 & 56 & 60 & 35 \\
\hline Chlorfenvinphos & 6.46 & 359 & 99 & 55 & 49 & 170 & 55 & 66 \\
\hline Propiconazole & 6.96 & 342 & 159 & 30 & 33 & 69 & 30 & 40 \\
\hline Fenamidon & 5.59 & 312 & 236 & 53 & 21 & 92 & 53 & 35 \\
\hline Phosphamidon & 5.02 & 300 & 174 & 49 & 34 & 132 & 49 & 34 \\
\hline Dimethoate & 4.90 & 230 & 171 & 30 & 21 & 199 & 30 & 14 \\
\hline Indoxacarb & 6.21 & 528 & 203 & 81 & 56 & 249 & 81 & 25 \\
\hline Omethoate & 4.64 & 214 & 125 & 45 & 35 & 109 & 45 & 42 \\
\hline Methomyl & 4.92 & 163 & 106 & 34 & 70 & 88 & 34 & 17 \\
\hline Chorantraniliprole & 5.34 & 482 & 451 & 68 & 28 & 283 & 68 & 25 \\
\hline Edifenphos & 6.67 & 311 & 283 & 61 & 20 & 109 & 61 & 46 \\
\hline Thiodicarb & 5.34 & 355.20 & 88 & 55 & 25 & 108 & 55 & 20 \\
\hline Trifloxystrobin & 6.57 & 409 & 186 & 47 & 26 & 186 & 47 & 22 \\
\hline
\end{tabular}

D.P. deculsting potential, E.P. entrance potential 
and $4 \mathrm{~g}$ anhydrous phthalate free $\mathrm{MgSO}_{4}$ were added to it. Reagents were thoroughly mixed by vortex mixer for $1 \mathrm{~min}$ and rotospinedfor $5 \mathrm{~min}$ and then centrifuged for 5 min @ 10,000 rpm speed. In the d-SPE clean-up step, $5 \mathrm{ml}$ supernatant was transferred to each of the $15 \mathrm{ml}$ centrifuge tubes containing $250 \mathrm{mg}$ PSA sorbent, $25 \mathrm{mg}$ $\mathrm{GCB}$ (for banana only) and $750 \mathrm{mg}$ anhydrous $\mathrm{MgSO}_{4}$. The tube was capped, vortexed for $30 \mathrm{~s}$ and centrifuged for 5 min @ 5000 rpm speed. $1 \mathrm{ml}$ supernatant was transferred into a vial for LC-MS/MS analysis and another portion was taken in atube and solvent was evaporated by Turbovap evaporator at $40^{\circ} \mathrm{C}$ and dried under a gentle stream of pure nitrogen. Finally, the residue was reconstituted in $1 \mathrm{ml}$ acetone and filtered through $0.2 \mu \mathrm{m}$ ultipore nylon 6, 6 membranes for GC-MS analysis. The same method was applied to the fortified and real samples.

\subsection{Validation as per Eurachemand SANTE guidelines}

The developed analytical method was validated with linearity, precision, accuracy, LOD, LOQ and measurement of uncertainty as per the recommendations of Eurachem [14] and SANTE guidelines [15]. LOD and LOQ were determined based on signal to noise ratio (S: N) 3:1 and 10:1 respectively. The five-point $\left(0.01-1.0 \mathrm{mg} \mathrm{kg}^{-1}\right)$ calibration curve was prepared for checking linearity with the regression coefficient $\left(R^{2}\right)$ for both pure and matrix-matched standard mixtures.Recovery experiment in seven replicates was carried out by fortifying $15 \mathrm{gm}$ homogenized fruit (apple, banana and guava) sample @ LOQ, $5 \times$ LOQ and $10 \times$ LOQ level (Table 3). Pesticides having similar LOQ as well as MRL values were fortified at LOQ/MRL level. Fortifications were done with the pure working standards. The quantification was done by matrix-matched standard to appraise the robustnessof the method.Theprecision of the method was evaluated by two steps (a) intra-day (repeatability) which is the analysis of the sample in five replicates in one day by one analyst and their value is calculated by percentage of relative standard deviation, (b) interday(reproducibility) analysis was done by two analysts with the same sample(five replicates)in two alternative day by following all the same experimental and instrumental conditions.The results of precision reproducibility are also calculated with the \%RSD. Precision actually asserted the trueness of the method by expressing the value as relative percentage deviation called \% RPD [16] @ LOQ level that can be represented by the following equation:

Relative percentage deviation (\%RPD)
Matrix effect can be evaluated by the following equation:

$\% \mathrm{ME}=(\mathrm{F}-1) \times 100$

$\mathrm{F}=\mathrm{S}_{\text {matrix }} / \mathrm{S}_{\text {standard}}$, where, $\mathrm{S}_{\text {matrix }}$ represents peak area of the fortified extract and $S_{\text {standard }}$ states peak area of the pure standard. Positive value of $\% \mathrm{ME}$ indicates matrix enhancement and negative value will be matrix suppression. For the strong matrix effect $\% M E>50,20<\% M E \leq 50$ having considered the medium matrix effect [17]. But currently $\% \mathrm{ME} \leq 20$ (enhancement or suppression) as per SANTEguideline is accepted.For the uncertainty measurement top down approach was used. The combined uncertainty that is associated with standard and sample was calculated as per the following equation:

$U c=\sqrt{\left(U_{1}^{2}+U_{2}^{2}+U_{3}^{2}+U_{4}^{2}+U_{5}^{2}+U_{6}^{2}+U_{7}^{2}+U_{8}^{2}+U_{9}^{2}+U_{10}^{2}+U_{11}^{2}\right)}$

Where, $U_{1=}$ recovery-accuracy, $U_{2=}$ recovery-precision, $\mathrm{U}_{3=}$ purity of standard, $\mathrm{U}_{4=}$ balance for standard preparation, $\mathrm{U}_{5=}$ volumetric flask for stock solution, $\mathrm{U}_{6}=$ volumetric flask for working standard solution, $U_{7=} 1 \mathrm{ml}$ pipette, $\mathrm{U}_{8=} 5 \mathrm{ml}$ pipette, $\mathrm{U}_{9}=$ linearity of balance, $\mathrm{U}_{10}=$ uncertainty of seven points calibration, $U_{11=}$ uncertainty precision of instrument at LOQ. Expanded uncertainty $(U)$ is twice of combined uncertainty at a confidence level of $95 \%$.

Total uncertainty $(\mathrm{MU})=\mathrm{LOQ} \times 2 \mathrm{Uc}$

\section{Results and Discussion}

\subsection{Standardization of Extractionand cleaning up step}

Carneiro and his co-workers [13] reported extraction process by modified QuEChERS but they did not use any clean-up step for banana matrix. Jardimaand her team [18] used buffer QuEChERS in apple and guava samples. In thepresent study, extracting solvent was standardized, among three different extracting solvents i.e., methanol, acetonitrile and ethyl-acetate used based on their polarities. A comparative picture of average percent recovery using these extracting solvents which provided the representative data was presented in Fig. 1. Based on the data, acetonitrile was standardised as the extracting solvent

$=[($ Interday recovery - Intraday recovery $) /($ Interday recovery + Intraday recovery $) / 2] \times 100$ 


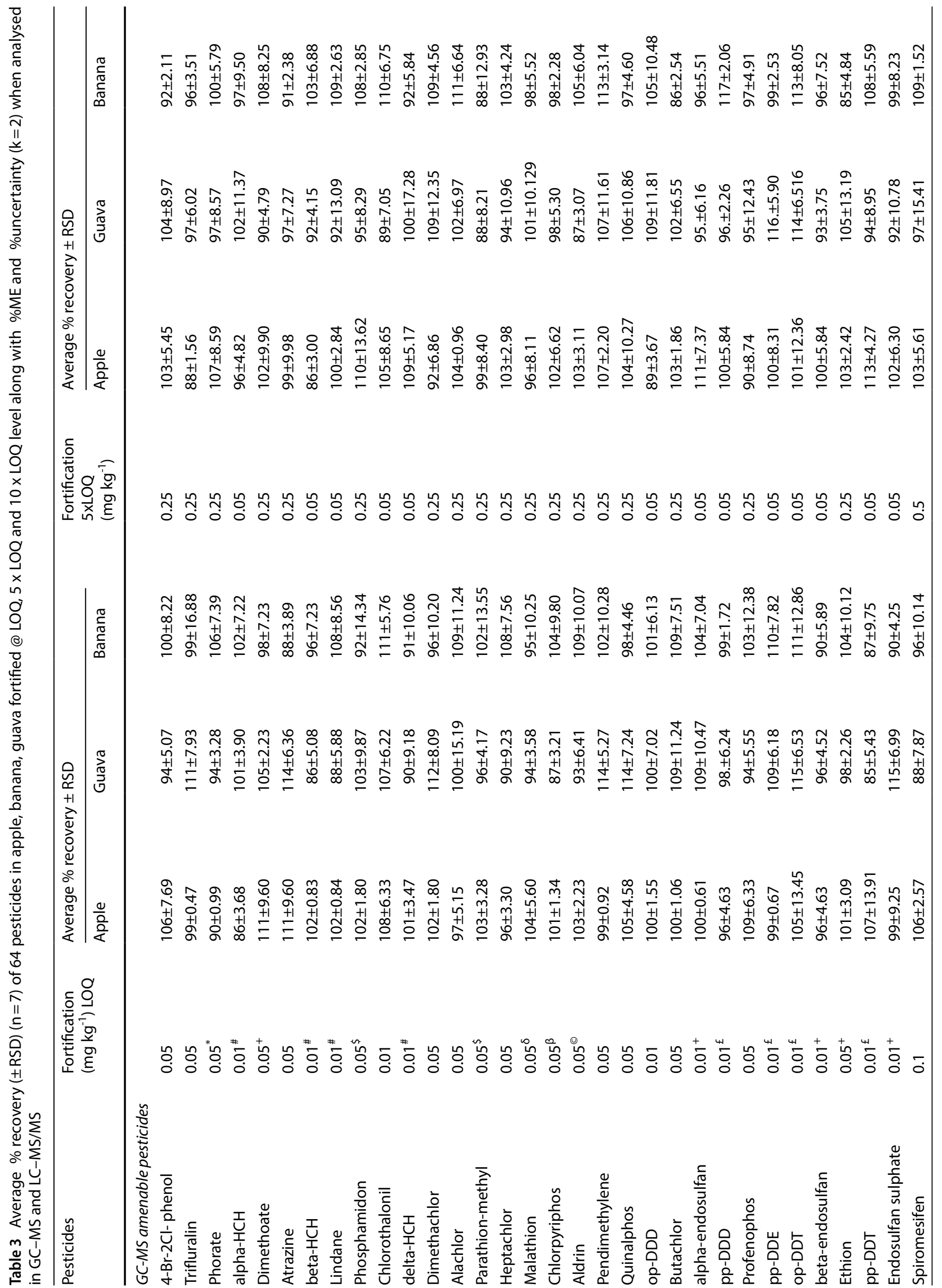




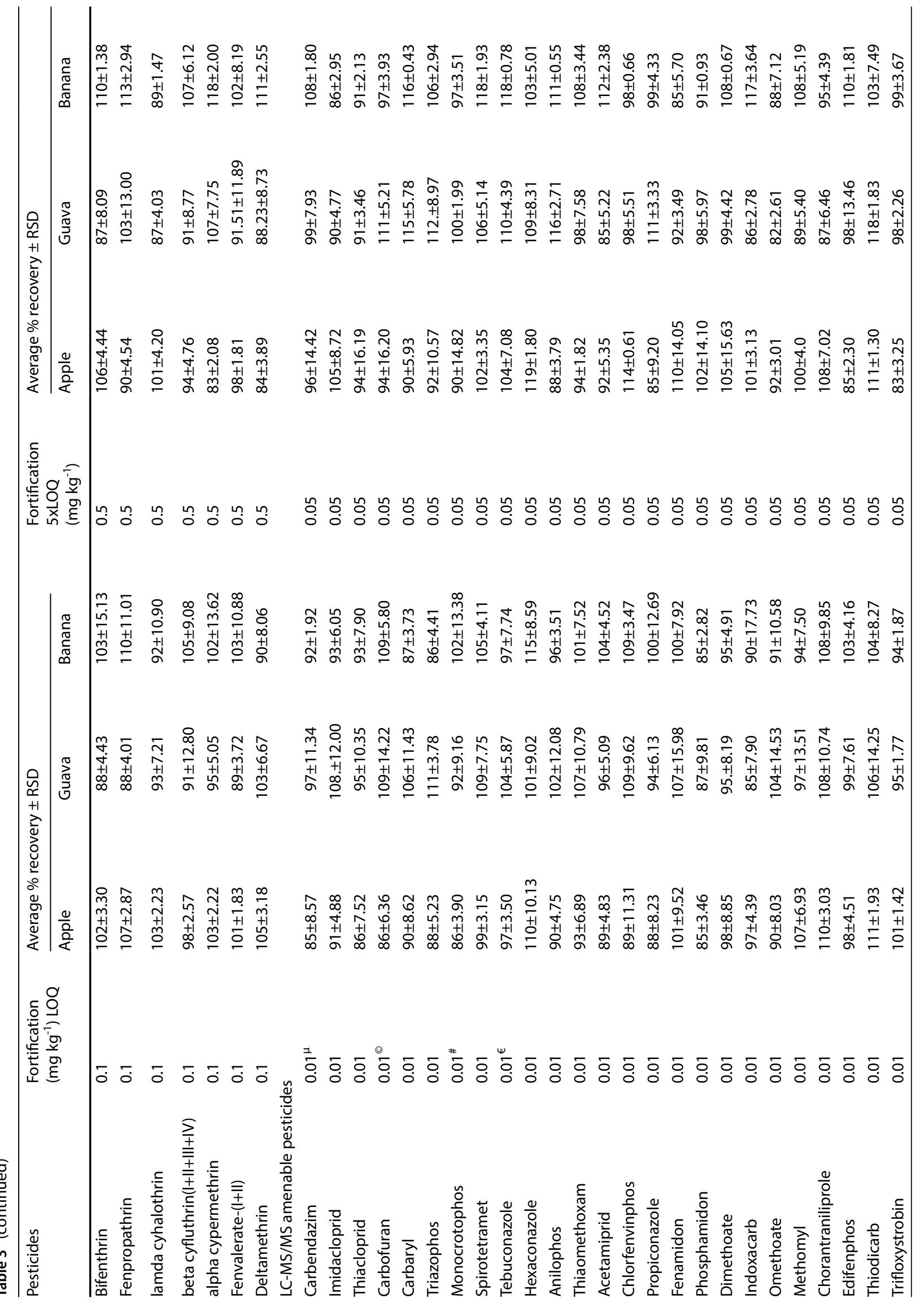




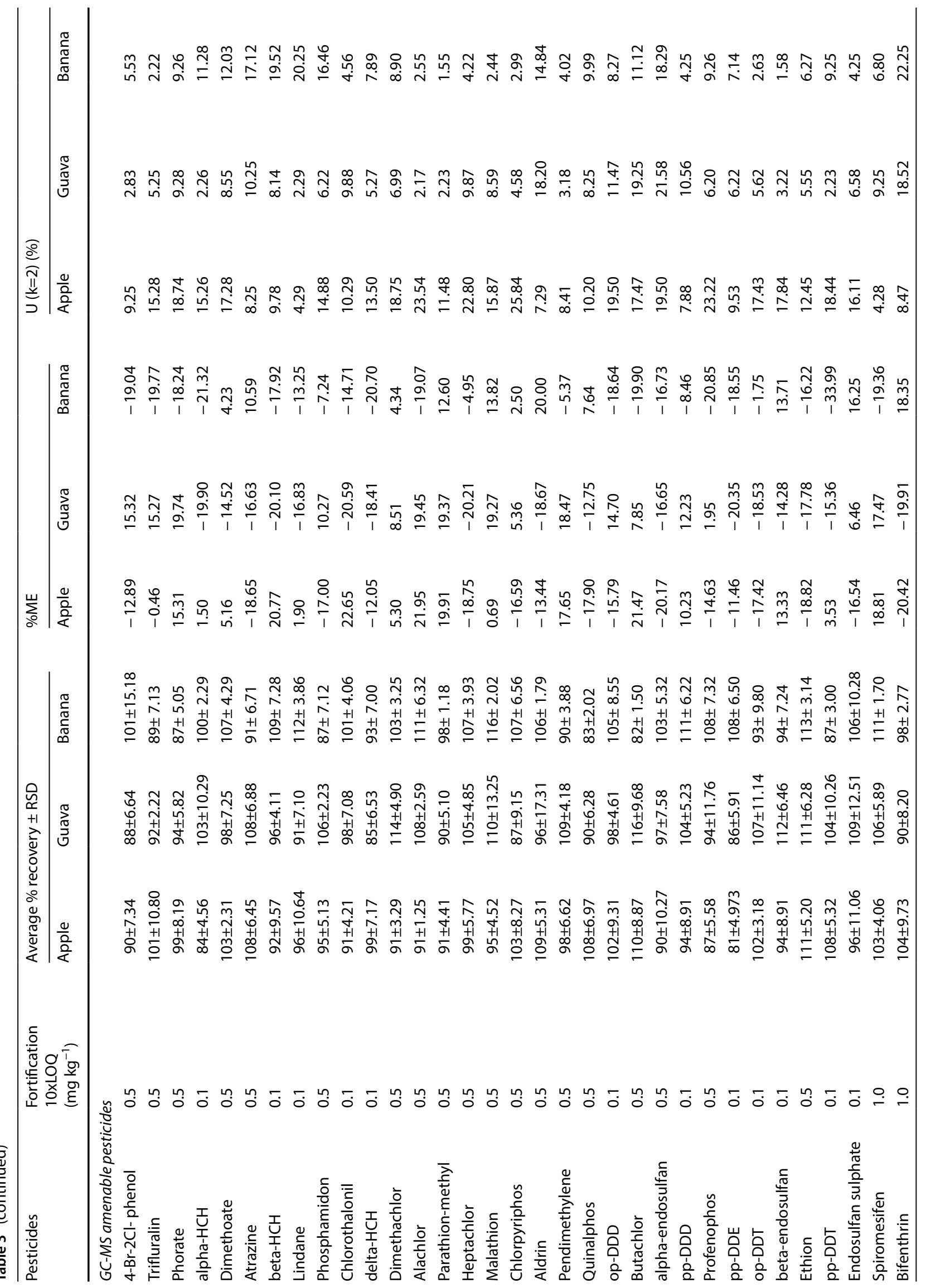




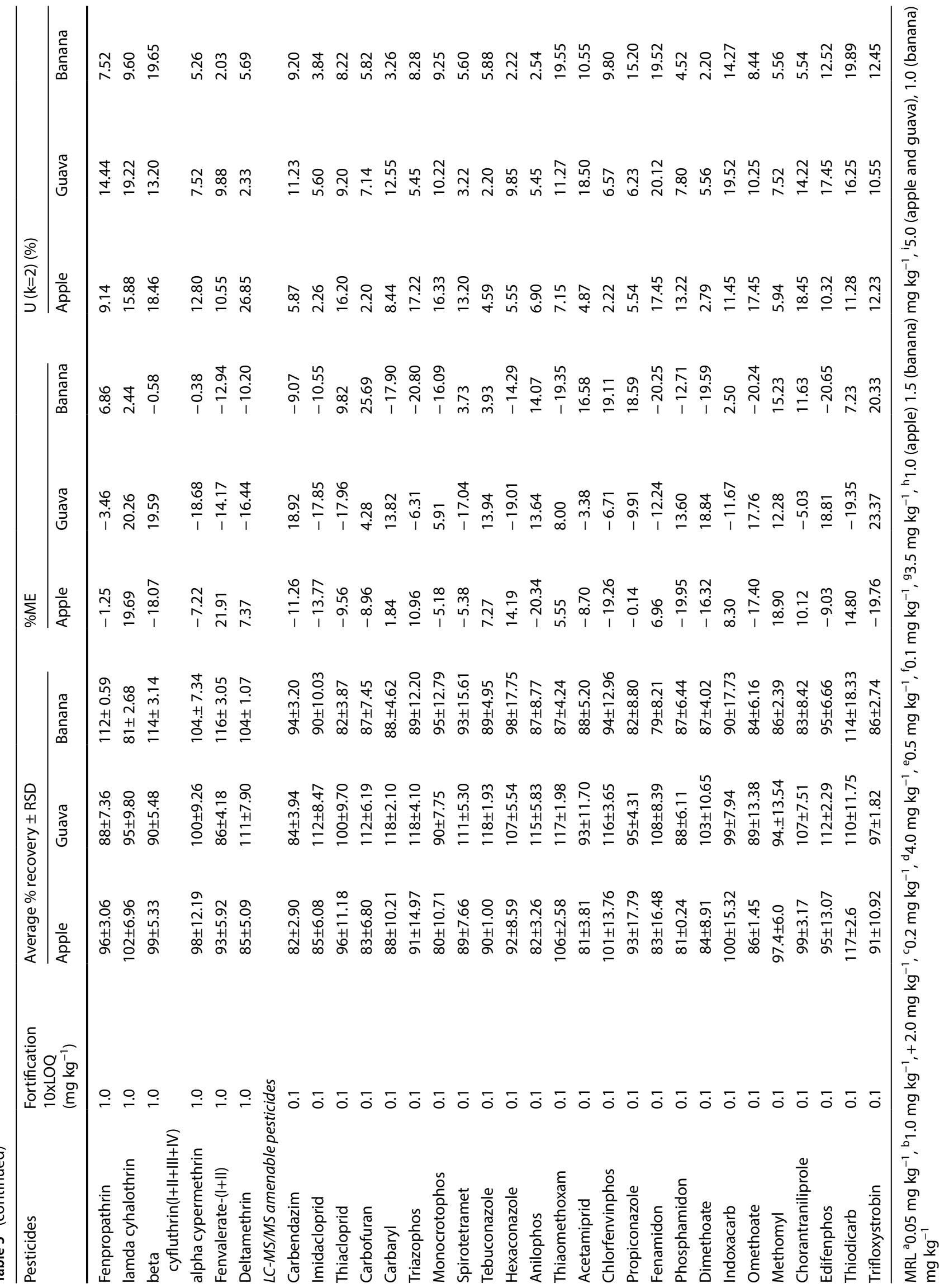



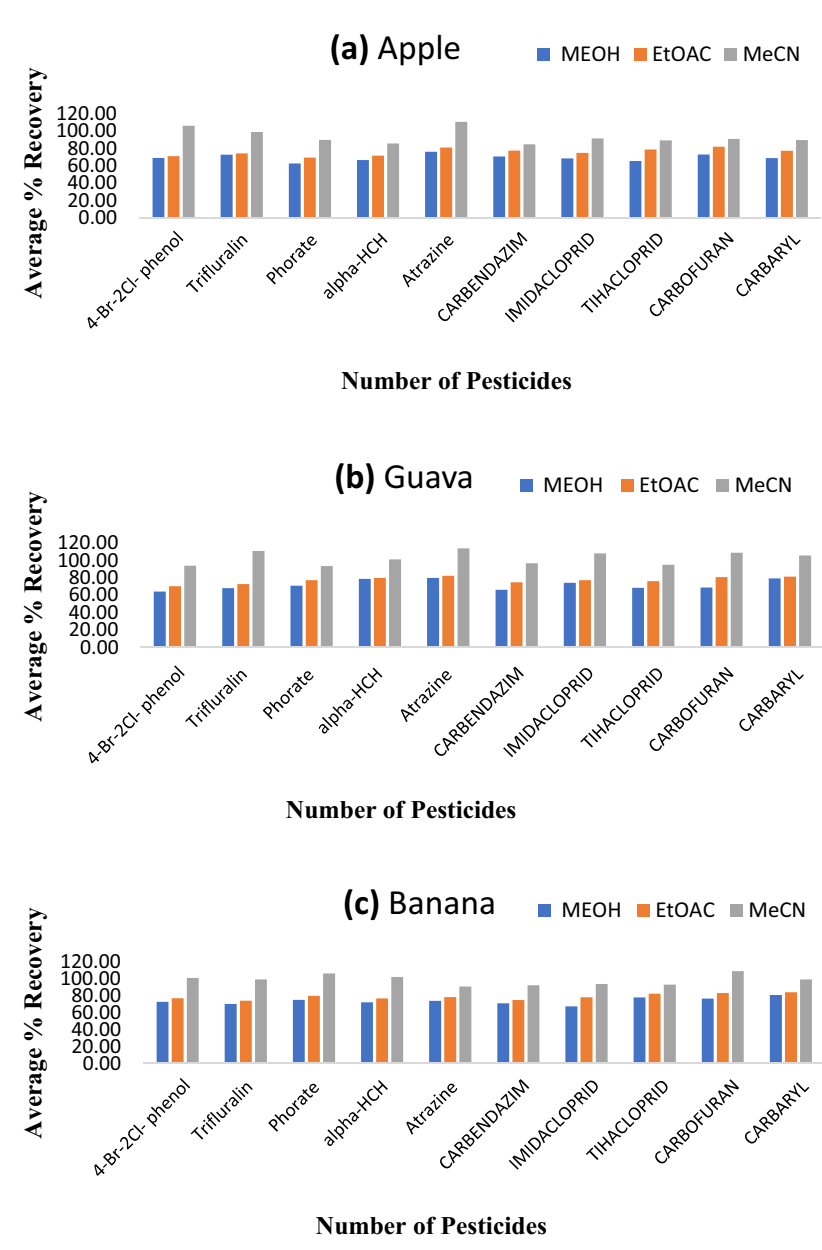

Fig. 1 Comparison of average \% recovery of 64 pesticides using $\mathrm{MeOH}, \mathrm{EtOAC}$ and MeCN as extracting solvents in case of $\mathbf{a}$ apple, $\mathbf{b}$ guava and $\mathbf{c}$ banana matrices fortified at LOQ level

because it gave the highest average percent recovery in all three matrices and for all the pesticides. The research works of [19-21] resulted the use of acetonitrile as good extracting solvent. Present studyusedPSAto absorb matrix co-extractives, $\mathrm{MgSO}_{4}$ to remove water and combination of PSA + GCB only for bananato remove heteropolysaccharide and carotenoids which areotherwisenot removed by PSA alone. Okihashiand his associates [22] reported the role of GCB in case of banana extract. Saito and his co-workers [23] also reported that the combination of $\mathrm{GCB}+\mathrm{PSA}$ provided excellent clean-up for removal of matrix materials. In our study, using GCB as cleaning up agent for banana matrices showed promising result. Without using GCB, beta-endosulfan (191.49\%), indoxacarb (124.77\%), trifloxystrobin (142.59\%) and Chorantraniliprole (81.81\%) suffered very high matrix enhancement effect. GCB reduced these values to $13.71 \%,-2.50 \%, 20.33 \%$ and $11.63 \%$ respectively. Some pesticides also suffered strong matrix suppression effects viz beta- $\mathrm{HCH}(-86.11 \%)$, alachlor (-81.40\%), pp-DDT(-30.09\%) and beta-cyfluthrin $(-48.74 \%)$ which were reduced to $-17.92 \%,-19.07 \%$, $-17.39 \%$ and $-0.58 \%$ respectively. Comparison of matrix effect in presence and absence of GCB in banana matrix was depicted in Fig. 2.

\subsection{Efficiency of the method}

A total of 39 pesticides were analysed in GC-MS. On the other hand, 25 pesticides were analysed in LC-MS/MS. In GC-MS analysis, at LOQ level, 86-111\%, 87-110\%, $84-114 \%$ recoverywas found respectively for apple, banana, guavawith respective relative standard deviation (RSD) ranging from 0.47 to $13.45 \%, 3.89$ to $16.88 \%$, 2.23 to $12.80 \%$.Irrespective of the pesticides and matrices, pp-DDT acquired the least recovery of $84.44 \%$ with RSD value $5.43 \%$. In GC-MS analysis, instrument parameters are standardized to increase the sensitivity and selectivity of the instrument. Considering the GC injection mode, split mode has been chosen to avoid the overloaded peaks that reduced the separation efficiency of the column. The GC oven temperature programming was standardized so that the analyte is well separated having good peak shape and the matrix interference is minimized to increase the sensitivity. Four different other methods were compared with the present methodregarding the standardization of GC-MS. The present method took 50 min run time in comparison to $70.33 \mathrm{~min}$ [16], $60.17 \mathrm{~min}$ [24], $60 \mathrm{~min}$ [25], $55 \mathrm{~min}$ [26]. The less run time ofthepresent method in comparison to others was established. Standardization of MS parameters was done by identification of peaks in total ion chromatogram of mixed standard solution in scan mode by their specific RT and characteristic mass fragmentation pattern. The most abundant ion that had the highest $\mathrm{S} / \mathrm{N}$ ratio and showed no matrix interference was selected as quantifier ion. The other two ions were selected as qualifier. A SIM method is prepared by fixing the RT window of each compound from the full scan chromatogram and the RT of individual compounds. Twenty-five pesticides, analysed in LC-MS/MS for apple, banana and guava matrices resulted the recovery range of $85-111 \%, 84-114 \%$ and $86-110 \%$ at LOQ levelrespectively with therespective RSD values of $1.42-11.31 \%$, $1.87-13.38 \%$ and $1.77-14.53 \%$. LC-MS/MS conditions have been standardized to achieve good separation, satisfactory selection and increased sensitivity which enable to analyse samples having complex matrices with a high degree of confidence. Different combination of mobile phases were tested because mobile phase has the direct effect on the peak shape and the retention time of the analyte in the column as well as on MS sensitivity. The different combination of water, methanol, acetonitrile with ammonium acetate, ammonium formate buffers were surveyed. 
Fig. 2 Comparison of \%ME of 64 pesticides while cleaning up with and without GCB in Banana matrix
\% Matrix Effect (ME) in Banana

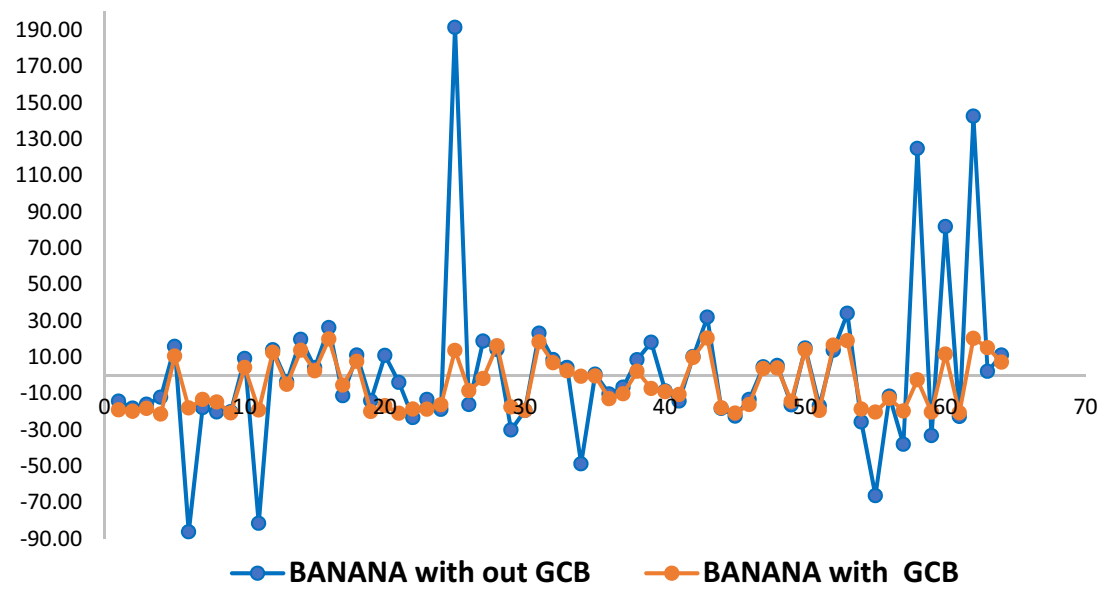

The well defined shape and reproducibility of retention time of pesticides were achieved by using mobile phase (A) water with $5 \mathrm{mM}$ ammonium formate (B) methanol with $5 \mathrm{mM}$ ammonium formate by using reverse phase Zorbax SB-C18 $(4.6 \times 150 \mathrm{~mm}, 5 \mu \mathrm{m})$ column.The total ion chromatograms (TIC) of $0.1 \mu \mathrm{g} \mathrm{ml}^{-1}$ for GC-MS and LC-MS/ MS are presented in Fig. 3.

\subsection{Method validation}

The LOD and LOQ of the GC amenable pesticides were found to be within the ranges of $0.001-0.04 \mathrm{mg} \mathrm{kg}^{-1}$ and $0.005-0.11 \mathrm{mg} \mathrm{kg}^{-1}$ respectively. The linearity of the calibration curve was established with $R^{2}$ value in the range of $0.988-0.999$. In case of $L C$ amenable pesticides, the values for $L O D, L O Q, R^{2}$ were within the range of $0.001-0.008 \mathrm{mg} \mathrm{kg}^{-1}, 0.008-0.01 \mathrm{mg} \mathrm{kg}^{-1}$ and $0.971-0.999$ respectively.The mean recoveries were found in the range of $80-120 \%$ (Table 3). Good accuracy was observed for all analytes with relative standard deviation $\leq 20 \%$ which is as per the requirements of SANTE regulating the performance of analytical method. Relative percentage deviation (\%RPD) was calculated for inter and intraday assay recovery for three matrixes at LOQ level. The recovery precision was expressed by averagerecovery percentage \pm SD along with RSD value. The inter- and intra-day precision of the method for apple matrix were found to be respectively $<13 \%$ and $<17 \%$ and $\%$ RPD value was $<12 \%$. For guava matrix respective inter and intraday valueswere $<16 \%$ and $<17 \%$ and $\%$ RPD value was $<10 \%$ and inter and intradayvaluesfor banana were $<19 \%$ and $<16 \%$ respectively and \%RPD value was $<18 \%$. All these values of precision satisfy SANTE and European Commissionguidelines (Fig. 4) and therefore the method is precise. To define the quality of analytical results, both traceability and degree of confidence are equally important. The uncertainty was determined at the LOQ level for all the pesticides as per the EURACHEM/CITAC (Table 3) showed $M U$ values for individual pesticides with the majority of compounds having uncertainties $<20 \%$. In apple, $\% \mathrm{ME}$ values ranged between $(-20.42$ and $22.65 \%)$ and therefore are almost within $\leq 20 \%$. The exceptions are chlorothalonil (22.65\%), alachlor (21.95\%), butachlor (21.75\%) and fenvalerate $(21.91 \%)$ which were undergonematrix enhancement effect. Whereas in guava, only one pesticide trifloxystrobinwas found to have matrix enhancement effect (23.37\%).All the \% ME values were presented in Table 3 for GC-MS and LC-MS/MS respectively. In case of banana, $15 \%$ pesticides showed matrix suppression effect out of 64 pesticides, whereas matrix enhancement effect was found for $12 \%$ pesticides. A comparison for banana matrix with presence and absence of GCB as cleaning up agent was designed for showing the matrix effect in Fig. 2.

\subsection{Analysis of real samples}

The method was successfully applied to analyse of market samplesof apple, banana, guavawhich were collected from four different districts (Kolkata, Howrah, Hooghly and Burdwan) of West Bengal, India and detected different numbers of pesticides (Table 4). Among the samples, guava collected from Pandua and Howrah were detected with chlorpyriphos $(0.25 \pm 6.19)$ and profenophos $(0.62 \pm 1.61)$ respectively. Two pesticides namely carbendazim $(0.9 \pm 2.32)$ and quinalphos $(0.12 \pm 1.26)$ were detected in banana samples collected from Howrah. Apple sample collected from Pandua was detected with dimethoate $(0.18 \pm 4.20)$. But apple sample collected from Kolkata was detected with three pesticides namely trifloxystrobin $(0.05 \pm 5.88)$, tebuconazole $(0.10 \pm 6.37)$ and carbendazim $(0.05 \pm 4.37)$. Therefore, highest numbers of pesticides 

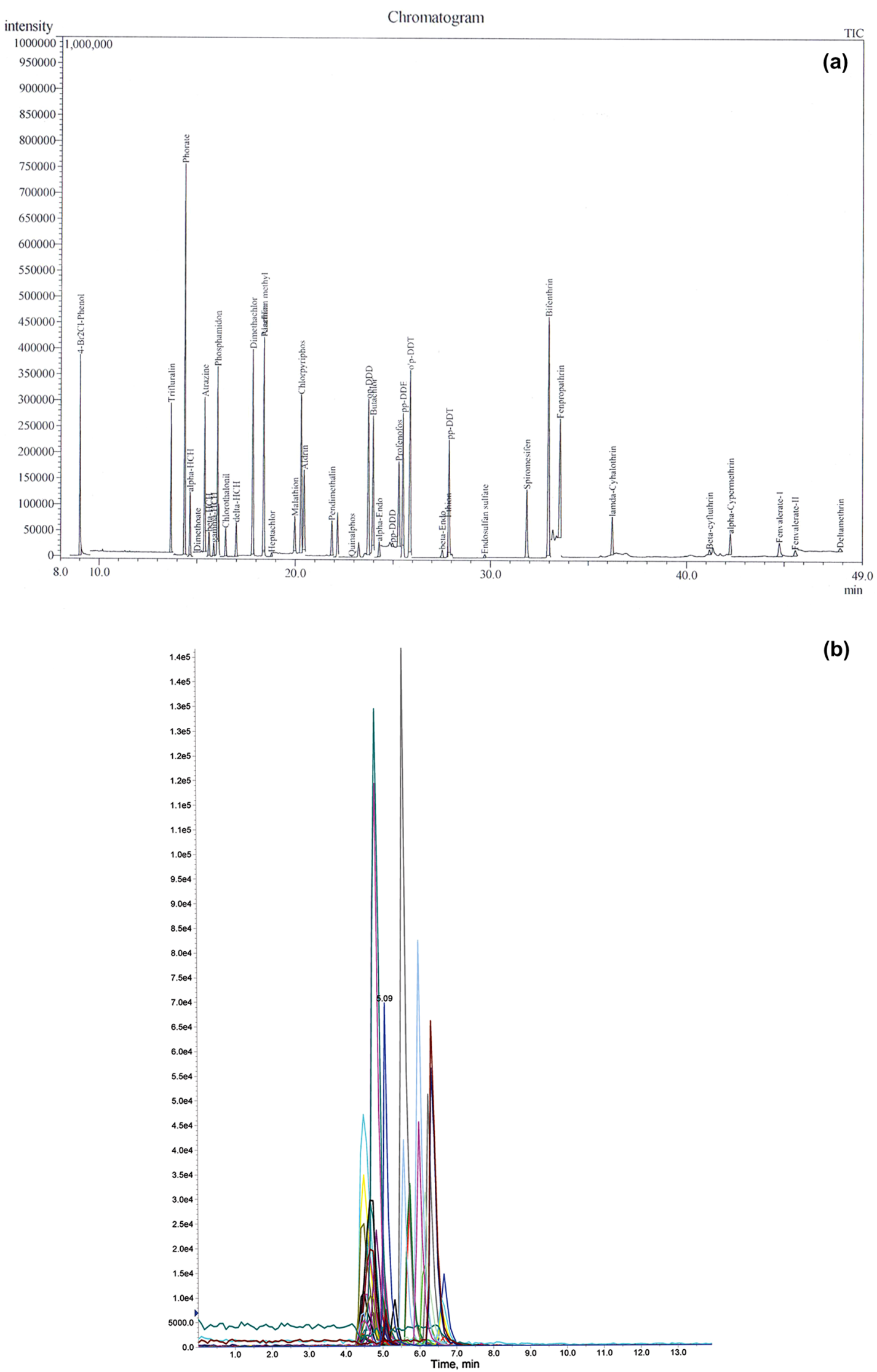

(b)

Fig. 3 TIC of 0.1 ugml- 1 of $\mathbf{a}$ GC-MS and $\mathbf{b}$ LC-MS/MS

\section{SN Applied Sciences}

A SPRINGER NATURE journal 
Fig. 4 Comparison of Inter and Intra- assay precision recovery of pesticide residues in apple, guava and banana matrixes

\section{Trueness (\% RPD) of pesticides in apple, guava and banana $(n=5)$ at LOQ levels}

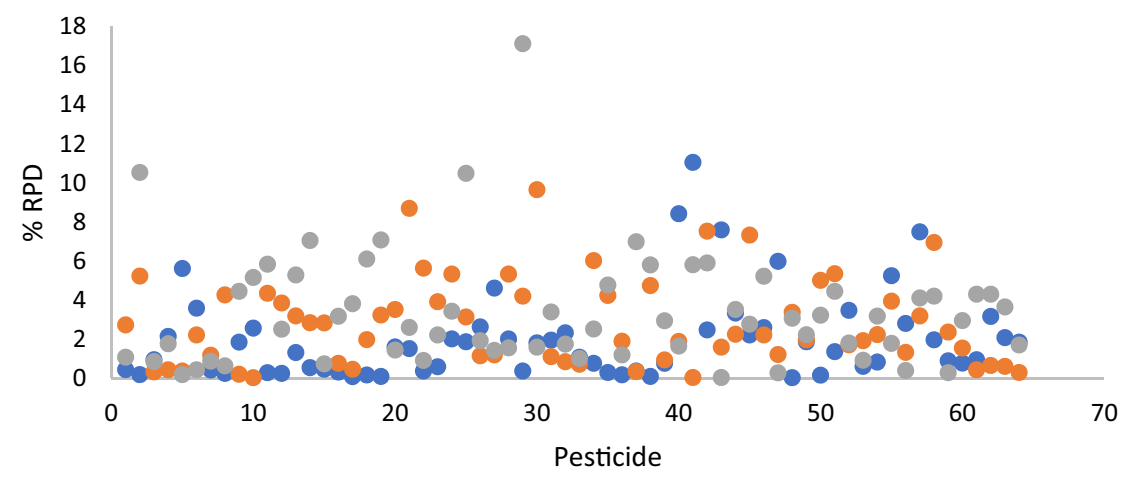

- Apple

- Guava

Banana
Table 4 Analysis of market samples of apple, banana and guava

\begin{tabular}{llllll}
\hline Location & Substrate & \multicolumn{2}{l}{ Number of samples } & Pesticides detected $\left(\mu \mathrm{g} \mathrm{g}^{-1} \pm \mathrm{RSD}\right)$ & $\begin{array}{l}\text { Mode of analysis } \\
\text { (GC-MS/LC-MS/MS) }\end{array}$ \\
\cline { 3 - 4 } & & Analysed & Detected & & \\
\hline Pandua & Apple & 12 & 01 & Dimethoate $(0.18 \pm 4.20)$ & GC-MS \\
Kolkata & Apple & 12 & 01 & $\begin{array}{l}\text { Trifloxystrobin }(0.05 \pm 5.88) \\
\text { Tebuconazole }(0.1 \pm 6.37)\end{array}$ & LC-MS/MS \\
& & & & Carbendazim $(0.05 \pm 4.37)$ & \\
Pandua & Guava & 12 & 01 & Chlorpyriphos $(0.25 \pm 6.19)$ & GC-MS \\
Hawrah & Guava & 12 & 01 & Profenophos $(0.62 \pm 1.61)$ & LC-MS/MS \\
Hawrah & Banana & 12 & $02(01+01)$ & Carbendazim $(0.09 \pm 2.32)$ & LC-MS/MS \\
& & & & Quinalphos $(0.12 \pm 1.26)$ & \\
\end{tabular}

(3) were detected in the apple samples collected from Kolkata.

\section{Conclusion}

In this era of good health and diet consciousness, food stuffs are being monitored regularly to check the presence of pesticide residues. A quick, accurate, precise and efficient method is therefore necessary to detect and determine pesticide residues in real samples. The present method is validated as per Eurachem [14] and SANTE guidelines [15]. The efficiencies of methanol, ethyl acetate and acetonitrile were checked as extracting solvents and finally acetonitrile was chosen as extracting solvent in the method. The use of GCB + PSA mixture as cleaning up agentin case of banana reduced the interference of heteropolysaccharide and carotenoids and thus nullified matrix interferences. The present method can be used for both the instruments at a time. This modified QuEChERS method is useful for quick determination of multiclass multipesticide residues in apple, guava and banana meant for export.

Funding The authors are grateful to Indian Council of Agricultural Research (ICAR), New Delhi, India for the financial support.

\section{Compliance with ethical standards}

Conflict of interest We all authors declare that we have no conflict of interest.

Human and animal rights This article does not contain any study with human participants or animals performed by any of the authors.

\section{References}

1. National Horticulture Board (2019). http://nhb.gov.in/statistics /Publication/Horticulture. Accessed 23 Aug 2019

2. Food and Agriculture Organization of the United Nation (2019). http://www.fao.org/faostat/en/data/PI. Accessed 23 Aug 2019 
3. Agricultural \& Processed Food Products Export Development Authority (2019). https://apeda.gov.in/apedawebsite Accessed 11 Aug 2019

4. Barriada-Pereira M, Concha-Graña E, González-Castro MJ, Muniategui-Lorenzo S, López-Mahía P, Prada-Rodríguez D, Fernández-Fernández E (2003) Microwave-assisted extraction versus Soxhlet extraction in the analysis of 21 organochlorine pesticides in plants. J Chromatogr A 1008:115-122

5. Zhao L, Szakas T, Churley M, Lucas D (2019) Multi-class multi-residue analysis of pesticides in edible oils by gas chromatographytandem mass spectrometry using liquid-liquid extraction and enhanced matrix removal lipid cartridge cleanup. J Chromatogr A 1584:1-12

6. Chatzimitakos TG, Anderson JL, Stalikas CD (2018) Matrix solidphase dispersion based on magnetic ionic liquids: an alternative sample preparation approach for the extraction of pesticides from vegetables. JChromatogr A 1581-1582:168-172

7. PylypiwH Arsenault T, Thetford C, Martina MJI (1997) Suitability of microwave-assisted extraction for multiresidue pesticide analysis of produce. J Agric Food Chem 45(9):3522-3528

8. Pan P, Liu WX, Shi X, Cao J, Shen WR, Qing BP, Sun R, Tao S (2004) Sample purification for analysis of organochlorine pesticides in sediment and fish muscle. J Environ Sci Health B 39:353-365

9. Sapozhnikova Y, Bawardi O, Schlenk D (2004) Pesticides and PCBs in sediments and fish from the Salton Sea, California, USA. Chemosphere 55:797-809

10. Fontanals N, Marce RM (2005) New hydrophilic materials for solid-phase extraction. Trends Anal Chem 24:394-406

11. Jordan TB, Nichols DS, Kerr NI (2006) Selection of SPE cartridge for automated solid-phase extraction of pesticides from water followed by liquid chromatography-tandem mass spectrometry. Anal Bioanal Chem 394:2257-2266

12. Anastassiades M, Lehotay SJ, Štajnbaher D, Schenck FJ (2003) Fast and easy multiresidue method employing acetonitrile extraction/partitioning and "dispersive solid-phase extraction" for the determination of pesticide residues in produce. J AOAC Int 86:412-431

13. Carneiro RP, Oliveira FAS, Madureira FD, Souza Silva G, Rde W, Lopes RP (2013) Development and method validation for determination of 128 pesticides in bananas by modified QuEChERS and UHPLC-MS/MS analysis. J Food Control 33:413-423

14. EURACHEM/CITAC Ellison SLR, Williams A (2012) In: Guide Quantifying Uncertainty in Analytical Measurement. 3rd ed.; Eds:1-141

15. SANTE/11813/2017. Guidance document on analytical quality control and validation procedures for pesticide residues analysis in food and feed. European Commission Directorate-General for Health andFoodSafety (rev.0).(https://ec.europa.eu/food/sites/ food/files/plant/docs/pesticides_mrl_guidelines_wrkdoc_201711813.pdf. Accessed 23 Aug 2019)
16. Tripathy V, Sharma K, Yadav R, Devi S (2019) Development, validation of QuEChERS-based method for simultaneous determination of multiclass pesticide residue in milk, and evaluation of the matrix effect. J Environ Sci Health B54:334-406

17. Savini S, Bandini M, Anna S (2019) An improved, rapid, and sensitive ultra-high-performance liquid chromatography-high-resolution orbitrap mass spectrometry analysis for the determination of highly polar pesticides and contaminants in processed fruits and vegetables. J Agric Food Chem 67(9):2716-2722

18. Jardim ANO, Mello DC, Goes FC, Junior EFF, Caldas ED (2014) Pesticide residues in cashew apple, guava, kaki and peach: GC$\mu E C D, G C-F P D$ and LC-MS/MS multiresidue method validation, analysis and cumulative acute risk assessment. J Food Chem 164:195-204

19. Dwivedi BC, Tiwari H, Gaur V (2017) Assessment of 27 pesticide residues in fruit juices $\&$ vegetables paste by gas chromatography with mass spectrometry (GC-MS). Int J Chem Stud 5(1):259-285

20. Chandra S, Mahindrakar AN, Kumar M, Shinde LP (2014) Determination of pesticide residues in fruits local market Nanded, India. Int J Advan Res 2:1075-1082

21. Lozowicka B, Rutkowska E, Jankowska M (2017) Influence of QuEChERS modifications on recovery and matrix effect during the multi-residue pesticide analysis in soil by GC/MS/MS and GC/ECD/NPD. Environ Sci Pollu Res 24:7124-7138

22. Okihashi M, Kitagawa Y, Akutsu K, Obana H, Tanaka Y (2005) Rapid method for the determination of 180 pesticide residues in foods by gas chromatography/mass spectrometry and flame photometric detection. J Pestic Sci 30(4):368-377

23. Saito Y, Kodama S, Matsunaga A, Yamamoto A (2004) Multiresidue determination of pesticides in agricultural products by gas chromatography/mass spectrometry with large volume injection. J AOAC Int 87:1356-1367

24. Hawari KEI, Mokh S, Iskandarani MAI, Halloum W, Jaber F (2019) Pesticide residues in Lebanese apples and health risk assessment. Food Addit Contam B 12:81-89

25. Rai S, Singh AK, Srivastava A, Yadav S, Siddiqui MH, Mudiam MKR (2016) Comparative evaluation of QuEChERS method coupled to DLLME extraction for the analysis of multiresidue pesticides in vegetables and fruits by gas chromatography-mass spectrometry. Food Anal Methods 9:2656-2669

26. Schwanz TG, Carpilovsky CK, Weis GCC, Costabeber IH (2019) Validation of a multi-residue method and estimation of measurement uncertainty of pesticides in drinking water using gas chromatography-mass spectrometry and liquid chromatography-tandem mass spectrometry. J Chromatogr A 1585:10-18

Publisher's Note Springer Nature remains neutral with regard to jurisdictional claims in published maps and institutional affiliations. 